\title{
Enfartes Esplénicos - quando a etiologia é multifactorial: Mutação do gene MTHFR e Trombocitose Essencial
}

\author{
Splenic Infarcts - When the cause is multifactorial: \\ MTHF gene mutation and Essential Thrombocytosis
}

\author{
Pereira $\mathrm{M}^{1}$, Morais $\mathrm{SA}^{1}$, Pereira $\mathrm{N}^{1}$, Lima $\mathrm{AL}^{2}$, Barreto $\mathrm{V}^{2}$ \\ 1 Interno de Formação Específica em Medicina Interna, Hospital Pedro Hispano, Matosinhos, Portugal \\ ${ }^{2}$ Assistente Hospitalar Graduado em Medicina Interna, Hospital Pedro Hispano, Matosinhos, Portugal
}

\begin{abstract}
Resumo
Introdução: A Trombocitose Essencial (TE) é uma doença mieloproliferativa crónica rara que apresenta risco acrescido de eventos trombóticos em $20-50 \%$ dos doentes. Em doentes com Hiperhomocisteinemia associada a mutação MTHFR em homozigotia, o risco acrescido para eventos trombóticos é de 1-2\%. Assim, a coexistência destas 2 entidades confere risco exponencial para ocorrência de fenómenos isquémicos.
\end{abstract}

Palabras clave: Trombosis, Trombocitosis esencial, MTHFR mutación, Infarto esplénico, Hiperhomocisteinemia.

\section{Introdução}

A trombocitose essencial (TE) é uma doença mieloproliferativa caracterizada por produção exagerada de plaquetas (>400.000). É a forma mais rara de doença mieloproliferativa crónica clonal (0,1 a 2,5/100000 hab/ano $)^{1,2}$, e afecta mais frequentemente 0 sexo feminino $(1,3: 1)^{1,3}$ e a faixa etária acima dos 50 anos, podendo estar associada a tendência trombótica ou hemorrágica ${ }^{1,2,3,4}$. A sua etiologia é desconhecida, sabendo-se apenas que, tal como acontece nas outras doenças mieloproliferativas crónicas, o processo clonal tem origem ao nível da célula-tronco hematopoiética totipotente ${ }^{1,2}$.

A apresentação clínica da TE é dominada por uma predisposição para eventos vasculares trombóticos e/ou hemorrágicos ${ }^{2}$. Os primeiros são francamente mais frequentes (20$50 \%$ ), sendo a idade avançada e a história prévia de eventos desta natureza os principais factores de risco ${ }^{1}$. Os eventos trombóticos ocorrem maioritariamente ao nível da microcirculação e território arterial (cerebral, coronário, membros), sendo os principais responsáveis pela morbimortalidade associada à $T E^{1,2}$. As complicações hemorrágicas são raras (menos de $10 \%$ dos doentes) ${ }^{1}$.

Entre 40 a $60 \%$ dos doentes com TE apresentam mutação do gene da tirosina cinase citoplasmática JAK21 1,4,5, cujo papel no aumento do risco trombótico é ainda pouco claro', sendo vários os estudos recentes em que se sugere uma relação causa-efeito, em particular em homozigotia ${ }^{5,6}$. No entanto, existem outros factores que também podem aumentar o risco trombótico associado à TE, nomeadamente factores trombofílicos hereditários, entre os quais se salientam a hiperhomocisteínemia e a mutação do gene da me-

\begin{abstract}
Essential thrombocythemia (ET) is a rare chronic myeloproliferative disease associated with an increased risk of thrombotic events in up to $50 \%$ of all patients. In patients with hyperhomocysteinemia associated with MTHFR mutation in homozigozity, the risk for thrombotic events is increased in $1-2 \%$. Therefore, the coexistence of these two clinical entities causes an exponential rise in the risk for ischemic phenomena.
\end{abstract}

Keywords: Thrombosis, Essential Thrombocythemia, MTHFR mutation, Splenic Infarcts, Hyperhomocysteinemia.

tiltetrahidrofolato reductase (MTHFR), uma enzima integrada no metabolismo do folato, essencial à replicação e divisão celular ${ }^{5}$. De facto, um valor aumentado de homocisteina, associado à mutação do gene MTHFR (em particular quando em homozigotia) está associado a um acréscimo das complicações trombóticas nos doentes com TE ${ }^{5,7}$.

Apresentamos 0 caso de um doente de 56 anos e história de doença cerebrovascular, admitido por dor abdominal intermitente com várias semanas de evolução, tendo sido documentadas áreas sugestivas de enfarte esplénico no estudo imagiologico. Foi constatada trombocitose, já presente em estudos analíticos prévios e, após extenso estudo, foi estabelecido o diagnóstico de TE. 0 rastreio de trombofilias foi também efectuado à admissão, pela história de eventos trombóticos major, e objectivou um aumento dos níveis de homocisteina, associado a mutação em homozigotia do gene MTHFR. Os eventos isquémicos identificados - enfartes esplénicos e doença cerebrovascular - foram assim interpretados como decorrentes do aumento do risco pro-trombótico, no contexto desta doença mieloproliferativa em associação a uma trombofilia hereditária. A identificação destas duas entidades nosológicas permitiu ainda intervir na profilaxia de novas complicações trombóticas, a principal causa de morbimortalidade neste contexto.

\section{Caso Clínico}

Doente do sexo masculino, 56 anos, dislipidémico e fumador activo (80 UMA), com doença arterial periférica documentada e história prévia sugestiva de doença cerebrovascular - episódio transitório de disartria e hemiparesia direita em 2011, com recuperação ad 
integro, e no mesmo ano, acidente vascular cerebral (AVC) isquémico em território da artéria cerebral média direita, com recuperação progressiva dos défices motores até à autonomia funcional. Sem história familiar de relevo. Duplamente antiagregado e sob estatina desde o AVC.

Foi admitido no Serviço de Urgência do Hospital Pedro Hispano em Março de 2013 por quadro de dor epigástrica e no hipocôndrio esquerdo com cerca de 2 dias de evolução, sem irradiação, constante e intensa, sem factores álgicos ou antálgicos, acompanhada de vómito alimentar. Descrevia ainda episódios prévios de dor abdominal com características semelhantes, embora transitórios, nos 2 meses prévios à admissão. Negados febre, sintomas constitucionais, alterações do transito intestinal, prurido, cefaleias recorrentes, parestesias ou sensação de queimor nas extremidades. Sem história de traumatismo abdominal.

À admissão com desconforto à palpação dos quadrantes abdominais esquerdos, sem organomegalias evidentes à palpação. Encontrava-se hemodinamicamente estável (TA 136/87 mmHg; FC 79 bpm), bem perfundido e com pulsos periféricos simétricos e amplos, apirético, com auscultação cardíaca rítmica e sem sopros, e auscultação pulmonar simétrica e sem ruídos adventícios. Não apresentava adenomegalias palpáveis ou alterações cutâneas, nomeadamente equimoses ou petéquias.

0 estudo analítico inicial permitiu documentar leucocitose (12900/ $\mu \mathrm{L}-60 \%$ de neutrófilos, 30\% de linfócitos), hemoglobina de 16,3 g/ $\mathrm{dL}$ e trombocitose $\left(570 \times 10^{3} / \mu \mathrm{L}\right)$, já documentada em estudos analíticos prévios. A proteína $\mathrm{C}$ reactiva apresentava elevação discreta (88 mg/L), com velocidade de sedimentação de $28 \mathrm{~mm} / 1^{\text {ahhora. Não }}$ foram documentadas alterações da função renal ou do ionograma. Os valores de DHL eram de $284 \mathrm{U} / \mathrm{L}$ (normal <220 U/L), e GGT de $208 \mathrm{U} / \mathrm{L}$ (normal <65 U/L). Não foi objectivada hiperbilirrubinemia, aumento das transaminases ou dos valores de amílase pancreática. Estudo da coagulação inicial sem alterações de relevo.

Foi realizado no Serviço de urgência estudo imagiológico complementar com ecografia abdominal e tomografia computorizada (TC) em que foi documentada esplenomegalia e várias áreas hipodensas subcapsulares esplénicas, a maior com $8 \mathrm{~cm}$ de maior diâmetro, sugestivas de enfarte, entretanto confirmado por ressonância magnética nuclear (RMN). Algumas destas lesões eram já objectiváveis em ecografia prévia (com cerca de 3 meses).

Perante estes achados, e tendo em conta a história anterior de eventos trombóticos e a trombocitose sustentada, foi realizado extenso estudo etiológico, tendo em vista exclusão das etiologias mais frequentes para este quadro, nomeadamente trombofilias, doença linfoproliferativa e fenómenos embólicos no contexto de endocardite, fibrilação auricular paroxística ou defeitos septais.

No rastreio de trombofilias, foi documentado um aumento dos valores de homocisteína (42.5 $\mathrm{mol} / \mathrm{L}$, normal inferior a $15 \mu \mathrm{mol} / \mathrm{L})$, com um défice concomitante de ácido fólico $(0,90 \mathrm{ng} / \mathrm{mL}$, normal inferior a 2,34 ng/mL). 0 estudo genético mostrou mutação de MTHFR c.677C>T em homozigotia.

A trombocitose manteve-se durante todo o internamento, com valores sustentadamente superiores a $450 \times 10^{3} / \mu \mathrm{L}$, tendo sido excluídas causas de trombocitose reactiva. 0 esfregaço de sangue periférico não mostrou quaisquer alterações, com leucócitos normais e sem poliglobulia. 0 mielograma e biópsia de medula óssea foram compatíveis com trombocitose essencial, com ligeira hipercelularidade medular e aumento de megacariócitos de formas atípicas e juvenis, por vezes em grupos, sem alterações das linhas mieloides e eritróides. Estudo citogenético foi positivo para a mutação JAK2 V612F (em heterozigotia) e a mutação bcr/ab/ negativa.

0 restante estudo realizado foi negativo, nomeadamente com exclusão activa de neoplasias e de endocardite infecciosa ou alterações cardíacas estruturais como fontes embólicas potenciais. 0 doente iniciou terapêutica com hidroxiureia e suplementos vitamínicos, e manteve antiagregação prévia, com boa resposta.

\section{Discussão}

0 presente caso relata a associação de duas entidades clínicas infrequentes, das quais decorre um aumento do risco trombótico, traduzido por enfartes esplénicos e doença cerebrovascular importante, e cuja abordagem foi desafiante. De facto, de entre os factores de risco para as doenças vasculares, a hiperhomocisteinemia tem vindo a apresentar um papel cada vez mais importante ${ }^{8}$, embora não tenha ainda sido possível definir claramente uma relação causal $^{5,7}$. 0 aumento dos valores séricos de homocisteína pode ocorrer por vários mecanismos como a alteração funcional das enzimas envolvidas no seu metabolismo (como

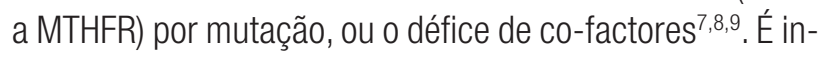
teressante verificar neste caso, que para além de estarem associadas duas condições pouco comuns que condicionam acréscimo do risco trombótico, o aumento dos níveis de homocisteina tem também dois contributos - 0 défice importante de ácido fólico, e a mutação do gene da MTHFR, em homozigotia, presente em cerca de $7 \%$ da população mundial $^{8}$. Nestes casos, são típicas as tromboses venosas profundas e o desenvolvimento de sintomas tradutores de doença ateroesclerótica entre a $3^{\mathrm{a}}$ e $4^{\mathrm{a}}$ décadas de vida. Para além da terapêutica citorredutora e antiagregante, 0 doente teve alta sob suplementação vitamínica, em particular com ácido fólico, tendo-se verificado uma normalização dos níveis de homocisteína, assim contribuindo para a redução do risco cardiovascular.

A par da documentação de trombofilia, este doente apresentava também trombocitose sustentada (pelas 450-600×103\% $\mu \mathrm{L})$, pelo menos nos dois anos prévios ao internamento, tendo sido este um dos problemas inicialmente abordados. Habitualmente, as causas de trombocitose são classificadas como clonais ou reactivas, sendo estas últimas mais frequentes ${ }^{1}$. Depois de excluídas as causas reactivas, e perante trombocitose persistente que documentámos neste caso, foi considerado o diagnóstico de patologia mieloproliferativa ${ }^{1}$. Os processos clonais mais frequentemente associados a trombocitose são TE, policitemia vera, mielofibrose primária e leucemia mieloide crónica ${ }^{1,2,5}$. Esta última é hoje facilmente distinguível dos restantes pela presença do cromossoma de Philadelphia (Ph+) e/ou da mutação bcr/abl, negativa neste doente, pelo que o diagnóstico foi limitado aos síndromes mieloproliferativos classicamente descritos como Ph negativos ou bcr/ab/ negativos ${ }^{2,3}$.

Para além da trombocitose sustentada, com exclusão de causas reactivas (défice de ferro, neoplasias, processo inflamatório crónico), foram verificados os restantes critérios 
definidos pela OMS (2008) para o diagnóstico de TE: biópsia óssea com proliferação da série megacariocítica sem alterações nas outras linhas celulares (em desfavor de outras neoplasias da série mieloide), e pesquisa da mutação JAK, marcador de monoclonalidade, positiva.

0 diagnóstico de TE enquadra, portanto, no contexto clínico deste doente, cuja apresentação inicial envolveu fenómenos trombóticos, descritos em até 50\% dos casos ${ }^{5}$. Estes eventos atingem frequentemente a microcirculação, condicionando sintomas vasomotores como a eritromelalgia ${ }^{10}$, mas podem igualmente envolver o território arterial ou venoso. Tal como se verificou neste caso, estas complicações podem assim traduzir-se em eventos trombóticos major, com envolvimento da circulação cerebral, coronária ou dos membros, e que acarretam habitualmente elevada morbimortalidade ${ }^{10}$. De facto, neste doente, o AVC e claudicação intermitente, que não foram interpretados previamente no contexto de um estado pro-trombótico (pelos factores de risco vascular presentes - tabagismo e dislipidemia), poderão ter sido as primeiras manifestações de TE. A patogénese destes fenómenos trombóticos não está bem compreendida, não existindo correlação clara com o grau de trombocitose ${ }^{1}$.

Como raramente se verifica a progressão para a leucemia ou mielofibrose e, apesar das complicações trombóticas referidas, os doentes com TE têm uma esperança de vida semelhante à da população geral ${ }^{1,3,5}$. Como tal, a chave no tratamento da TE reside na profilaxia dos eventos trombóti$\cos ^{1,3}$. Neste doente, é interessante reflectir na terapêutica a longo prazo, tendo em conta que os enfartes esplénicos ocorreram sob dupla antiagregação. Sendo este considerado, pelos critérios da OMS, um doente com alto risco de eventos trombóticos, foi associada à terapêutica antiagregante 0 efeito citorredutor da hidroxiureia, com bons resultados ${ }^{3,4}$. Tal como previamente referido, a suplementação vitamínica condicionou também a normalização dos valores de homocisteína, medidas que, como um todo, permitiram optimizar o risco vascular do doente, que entretanto cessou também hábitos tabágicos. Tem vindo a apresentar-se clinicamente bem, sem novas intercorrências, nomeadamente no que diz respeito a eventos trombóticos.

Destacamos, com este caso clínico a importância do diagnóstico e início de terapêutica precoces na TE, mesmo em doentes sem expressão clínica evidente, que permite a prevenção de complicações trombóticas. Para além disto, salienta-se aqui a importância do rastreio de trombofilias nos doentes com TE, particularmente se contemporâneo ao rastreio de outros factores de risco para trombose, porque todos eles poderão contribuir para amplificar o risco trombótico global, independente da TE.

\section{Agradecimentos}

Os autores gostariam de agradecer o apoio do Dr. Jorge Martins (AH Medicina Interna) pelo apoio incondicional na elaboração deste trabalho.

\section{Referências}

1. Baleiras C, Silva A, Serrano F. Trombocitémia essencial e gravidez. Acta Med Port 2003; 16:87-91.

2. Brière JB. Essential thrombocythemia. Orphanet J Rare Dis 2007; 2:3-20.

3. Tefferi A. CME information: Polycytemia Vera and Essential Thrombocythemia 2015 update on diagnosis, risk-stratification and management. Am J Hematol 2015; 90:163-73.

4. Oki M, Moriuchi M, Kawada H, Ogama Y, Ondo K. A case of essential thrombocythemia presenting with aortic thrombosis. Tokai J Exp Clin Med 2008; 33:135-7.

5. Bittencourt RI, Poncelet K, Almeida ACC, Fassina K, Onsten TG. Trombocitose essencial: 0 que é essencial saber. Rev Bras Hematol Hemoter 2010; 32:162-170.

6. Qin Y, Wang X, Zhao C, Wang C, Yang Y. The impact of JAK2V617F mutation on different types of thrombosis risk in patients with essential thrombocythemia: a meta-analysis. Int J Hematol 2015 [Epub ahead of print].

7. Sokolowska B, Nowaczynska A, Bykowska K, Chocholska S, Wejksza K, Walter-Groneck $A$. JAK2 mutation status, hemostatic risk factos and thrombophilic factos in essential thrombocythemia (ET) patients. Folia Histochemica et Cytobiologica 2011; 49:267-71.

8. Panico MD. Hyperhomocysteinemia and vascular disease. J Vasc Br 2004; 3:3-4.

9. Cui T. MTHFR C677T mutation increased the risk of ischemic stroke especially in large-artery atherosclerosis in adults: an update meta-analysis from 38 researches. Int J Neurosci 2015 [Epub ahead of print].

10. Malecki R, Gacka M, Kuliszkiewicz-Janus M, Jakobsche-Policht U, Kwiatkowsk J. Adamiec R. Altered plasma fibril clot properties in essential thrombocythemia. Platelets 2015 [Epub ahead of print]. 